\title{
The impact of deuterium oxide on the properties of resorcinol- formaldehyde gels
}

\author{
Martin Prostredny ${ }^{1} \cdot$ Jack Ballantine ${ }^{1} \cdot$ Jan Sefcik ${ }^{1} \cdot$ Ashleigh J. Fletcher $\mathbb{D}^{1}$ \\ Received: 30 November 2017 / Accepted: 19 January 2018 / Published online: 12 February 2018 \\ (c) The Author(s) 2018. This article is an open access publication
}

\begin{abstract}
Resorcinol-formaldehyde gels offer a range of properties that can be exploited in a variety of applications, but better understanding of gel formation mechanisms is needed to enable rational control and optimisation of the physico-chemical characteristics of these materials. Our previous studies have focussed on investigating the formation pathways of these gels, using nuclear magnetic resonance and dynamic light-scattering techniques, as well as evaluating their final physical and chemical properties, via sorption and spectroscopic methods. Nuclear magnetic resonance has been used over the years to probe the chemical species formed during resorcinol-formaldehyde gel polymerisation, but the technique typically involves the prior addition of deuterium oxide to provide a deuterium lock for NMR measurements. However, the effect of deuterium oxide to resorcinol-formaldehyde systems is currently unknown, although the substitution of water by deuterium oxide has been previously reported to alter the chemical and physical properties of reacting systems. In this work we examine the effect of adding deuterium oxide to resorcinol-formaldehyde sol-gel synthesis at different dilution levels and the impact that this addition has on the final characteristics of the synthesised gels, in order to assess the validity of using NMR with a deuterium lock for the investigation of polymerisation mechanism in resorcinol-formaldehyde sol-gel processes.
\end{abstract}

\section{Graphical Abstract}
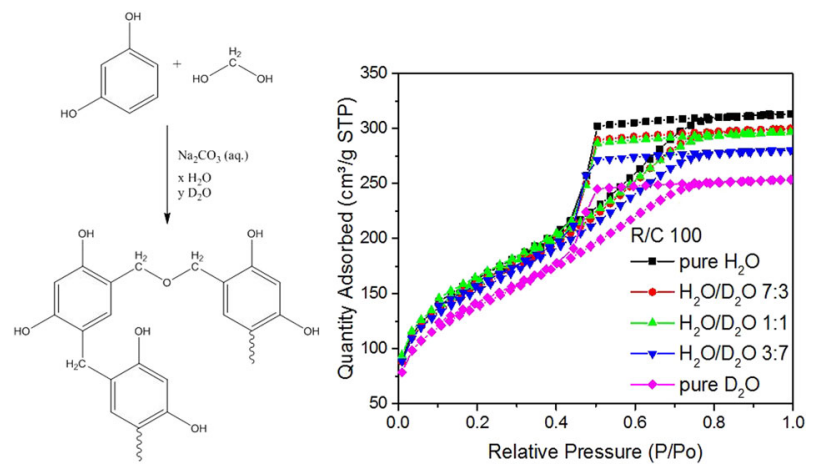

Keywords Isotope effect $\cdot$ Nuclear magnetic resonance $\cdot$ Xerogel $\cdot$ BET $\cdot$ Adsorption isotherm $\cdot$ Pore size

\section{Highlights}

- Successful synthesis of resorcinol-formaldehyde gels using $\mathrm{D}_{2} \mathrm{O}$ as synthetic solvent

- $\mathrm{D}_{2} \mathrm{O}$ shown to have insignificant effect on resorcinol-formaldehyde gel properties

Ashleigh J. Fletcher

ashleigh.fletcher@strath.ac.uk

1 Department of Chemical and Process Engineering, University of Strathclyde, 75 Montrose Street, Glasgow G1 1XJ, UK 
- High catalyst concentration systems less affected due to shorter gelation times

- Low catalyst concentration systems more greatly affected due to weaker structure

- Established use of $\mathrm{D}_{2} \mathrm{O}$ in NMR studies of resorcinol-formaldehyde gels has minimal impact

\section{Introduction}

Resorcinol-formaldehyde (RF) gels were originally discovered a few decades ago [1]; however, despite numerous previous studies into the preparation and use of these materials, the mechanism of RF gel formation is still not fully understood. The original base-mediated procedure, using sodium carbonate, proposed by Pekala [1], is still one of the most commonly used [2-6]. It should be noted that the description of sodium carbonate, other metal carbonates or other bases used in the synthesis of RF gels as catalysts is not accurate, as these species are not recoverable after gel formation. However, following the convention of nomenclature within this field, the term catalyst will be used in this paper to refer to the base, here sodium carbonate, added to the synthetic matrix. In the synthesis of RF gels, the first step is an addition of formaldehyde to resorcinol. In a basic solution, resorcinol forms an anion with the negative charge concentrated at the ortho and para positions of the benzene ring. Consequently, positions next to these sites become chemically activated and subsequently react with formaldehyde. However, formaldehyde is present in a hydrated form as methylene glycol and its oligomers in aqueous solutions used in RF gel synthesis [7] and thus a range of hydroxymethyl derivatives are formed in the initial reaction step [8], as shown in Fig. 1.

This step is conventionally thought to be followed by a polycondensation reaction between hydroxymethyl derivatives [4]. However, we have recently established that the gel formation process involves a more subtle interplay of chemical and physical processes, where nanoscale clusters assemble early on in the at temperatures in excess of $55^{\circ} \mathrm{C}$ [2], whereas no condensation products can be seen using liquid phase nuclear magnetic resonance (NMR) [8]. These clusters appear at elevated temperatures due to microphase separation or formation of mesostructured liquid phases containing initial hydroxymethyl resorcinol derivatives. Subsequent polycondensation is most likely to proceed within these clusters, which grow over time, as observed by dynamic light scattering until they fill the available space in the solution and/or there is complete consumption of at least one reactant. Depending on the amount of catalyst used, these clusters grow to different sizes. At higher R/C ratios (less catalyst), RF clusters grow into larger sizes, thereby leading to larger voids between the clusters as compared to lower R/C ratios (more catalyst) [2]. However, regardless of the catalyst concentration used, the reactions resulting in the formation and growth of the RF clusters remain the same, where the initial stages are chemically controlled processes, followed by the physical formation and aggregation of clusters, thereby highlighting the interplay between chemistry and physics in development of the microstructure of RF gels.

As mentioned above, speciation at various stages of RF polymerisation has been previously probed, in order to better understand the processes involved in formation of RF gels, and reactions between formaldehyde and resorcinol have been studied using NMR. The species present in RF mixtures have been previously investigated by several researchers, including Werstler [9] who used ${ }^{13} \mathrm{C}$ NMR (diluting samples by $20 \%$, assumed here by volume, with $\mathrm{D}_{2} \mathrm{O}$ ), Christiansen [10] again using ${ }^{13} \mathrm{C}$ NMR (with 20\% of solvent weight comprised of $\mathrm{D}_{2} \mathrm{O}$ ), and more recently by Lewicki et al. [11] using ${ }^{1} \mathrm{H}$ NMR (with samples quenched in deuterated DMSO- $\mathrm{d}_{6}$ ) and by Gaca et al. [8] using a combination of ${ }^{1} \mathrm{H},{ }^{13} \mathrm{C}$ and $2 \mathrm{D}[1 \mathrm{H}, 13 \mathrm{C}]$ heteronuclear single quantum coherence (HSQC) NMR (with samples prepared using water/ $\mathrm{D}_{2} \mathrm{O}(7: 3 \mathrm{v} / \mathrm{v})$ mixtures). We also investigated speciation in aqueous methanolic formaldehyde solutions using ${ }^{1} \mathrm{H},{ }^{13} \mathrm{C}$ and $2 \mathrm{D}[1 \mathrm{H}, 13 \mathrm{C}]$ HSQC NMR (with samples prepared using water/ $\mathrm{D}_{2} \mathrm{O}(7: 3$ $\mathrm{v} / \mathrm{v}$ ) mixtures) under conditions used for RF polymerization, allowing the development of a detailed thermodynamic model accounting for oligomerization of methylene glycol species in such solutions [7]. Rivlin et al. [12] also recently investigated kinetics and equilibria in $\mathrm{D}_{2} \mathrm{O}$ solutions of formaldehyde using ${ }^{1} \mathrm{H}$ and ${ }^{13} \mathrm{C}$ NMR, providing equilibrium and rate constants of formaldehyde-based species.

As can be seen from previous literature, up to $20-30 \%$ of solvent by volume has been used to obtain a deuterium lock for NMR measurements, even in nominally aqueous solutions. However, it is well known that substitution of $\mathrm{D}_{2} \mathrm{O}$ for $\mathrm{H}_{2} \mathrm{O}$ may affect chemical and/or physical processes due to its different molecular weight, interactions (e.g., hydrogen bonding), density, viscosity, etc. This is generally ascribed to the differences in the hydrogen-bonded structures of $\mathrm{D}_{2} \mathrm{O}$ and $\mathrm{H}_{2} \mathrm{O}$, as reflected in many thermodynamic properties [13], and results from differences in the zero-point energy of the two species as a consequence of the dissimilarity in mass $[14,15]$. Diffusional rate differences have long been related to mass differences [16], where the heavier species exhibits reduced mobility. However, there are many instances where substitution with a heavier isotope results in an increase in the rate of a process, known as an inverse isotope effect, as observed in a variety of systems [17-21]. It has also been reported that hydrophobic effects are more pronounced in $\mathrm{D}_{2} \mathrm{O}$ compared with $\mathrm{H}_{2} \mathrm{O}[22,23]$ and the presence of $\mathrm{D}_{2} \mathrm{O}$ can have an effect on phase separation temperature of 


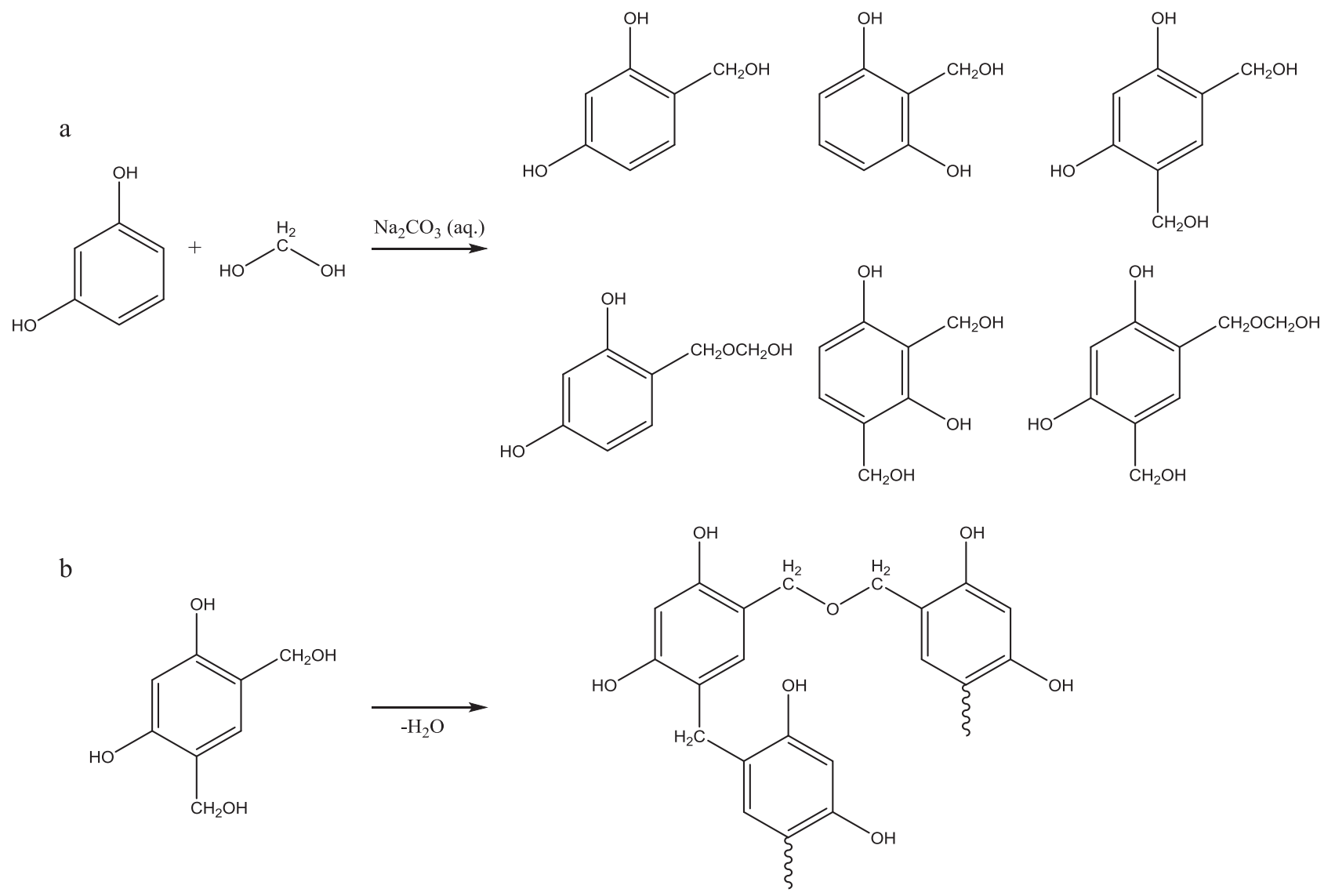

Fig. 1 a Reaction of resorcinol with formaldehyde in a basic aqueous solution showing number of different derivatives present in solution followed by $\mathbf{b}$ an example condensation reaction between hydroxymethyl derivatives

microemulsions [24], both of which would have an effect on the microphase separation of clusters during formation of RF gels. Hence, microstructure formation processes present in sol-gel systems, resulting from the interplay of chemical and physical processes, may be influenced by the mere presence of $\mathrm{D}_{2} \mathrm{O}$, as well as the quantitative amount of $\mathrm{D}_{2} \mathrm{O}$ added to reaction mixtures, with the directionality of the effect also unknown; this may, therefore, limit the validity of insights about polymerisation and structure formation mechanisms obtained from previous NMR studies. It is imperative that these systems are studied in the gel form to eliminate any additional effects incurred by post-gel treatment, e.g., carbonisation. In this work we aim to assess the effects of added $\mathrm{D}_{2} \mathrm{O}$ in RF sol-gel reaction mixtures on properties of resulting xerogels with a view to validating the use of NMR as a probe technique for the study of RF gels specifically, as well as a model for other polymeric materials.

\section{Sample preparation}

All RF gel samples were prepared using a procedure developed previously [2]. In order to investigate the influence of deuterium oxide $\left(\mathrm{D}_{2} \mathrm{O}\right)$ on the final properties of RF gels, samples with different $\mathrm{H}_{2} \mathrm{O} / \mathrm{D}_{2} \mathrm{O}$ volumetric ratios were synthesized. Only water added to the system was taken into account for the ratio, omitting any water contributed by the formaldehyde stock solution. Samples with following $\mathrm{H}_{2} \mathrm{O} / \mathrm{D}_{2} \mathrm{O}$ v/v ratios were prepared: $1: 0$ (pure water), $7: 3,1: 1$, and $0: 1$ (pure $\mathrm{D}_{2} \mathrm{O}$ ). These values were chosen in order to bracket values used in previous studies [8-10], where $30 \% \mathrm{D}_{2} \mathrm{O}$ was the highest dilution used by Gaca et al. [8]. All chemicals were used as received and deionised water was produced in-house (Millipore Elix 5 with Progard 2).

First, the appropriate amount of resorcinol (SigmaAldrich, ReagentPlus, 99\%) was added to a premeasured volume of deionised water and/or $\mathrm{D}_{2} \mathrm{O}$ (SigmaAldrich, 99.9 atom $\%$ D) in a jar containing a magnetic stirrer bar. Upon dissolution of all of the added resorcinol, a corresponding amount of sodium carbonate (SigmaAldrich, anhydrous, $\geq$ $99.5 \%$ ), on a molar basis, was weighed out and added to the solution. Sodium carbonate drives the reaction by a combination of increasing the solution $\mathrm{pH}$ in the basic region, via hydrolysis of the carbonate ion, and by the introduction of sodium ions, which it has been suggested 
assist the addition of formaldehyde to resorcinol [25]. As previously mentioned, sodium carbonate is termed a catalyst and its concentration is expressed as resorcinol/catalyst molar ratio (R/C) and $\mathrm{R} / \mathrm{C}$ values of 100,300 and 600 were studied here. After all the solids were dissolved, the required amount of stock formaldehyde solution (SigmaAldrich, $37 \mathrm{wt} \%$ formaldehyde in water, containing $10-15 \mathrm{wt} \%$ methanol as a formaldehyde polymerisation inhibitor) was added and the solution stirred in a closed jar for $30 \mathrm{~min}$. All samples were prepared with $20 \mathrm{w} / \mathrm{v} \%$ solids content and the total volume used was $30 \mathrm{ml}$, composed of water, deuterium oxide and methanol, contributed by the formalin solution used. At the end of the period of agitation, the stirrer bar was removed from the solution and the jar lid was hand tightened, before moving the jar to an oven (Memmert UFE400) preheated to $85^{\circ} \mathrm{C}$. Samples formed during this study gelled within 1-2 $\mathrm{h}$ [2], established by the lack of flow within the mixture when the jar was tilted at a $45^{\circ}$ angle; however, samples were left to cure for 3 days in order to ensure sufficient time for crosslinking to occur. After 3 days, the jars containing the gels were removed from the oven and left to cool to room temperature. The formed gels were cut into smaller pieces before washing and solvent exchange with acetone (SigmaAldrich, $\geq$ 99.5\%). Standard solvent exchange involved addition of $40 \mathrm{ml}$ of acetone to the gel, before resealing the lid and, in order to minimise acetone losses, wrapping the jar/lid junction with paraffin film. Sealed jars were put on a shaker unit (VWR 3500 Analog Orbital Shaker) and agitated for 3 days. Each successive day, the exchanged acetone was drained and replaced with $40 \mathrm{ml}$ of fresh solvent. After 3 days of solvent exchanging, the gel was drained and placed in a vacuum oven (Towson and Mercer 1425 Digital Vacuum Oven), preheated to $85^{\circ} \mathrm{C}$, to dry for 2 days. Finally, the sample was transferred to a labelled sample tube for storage.

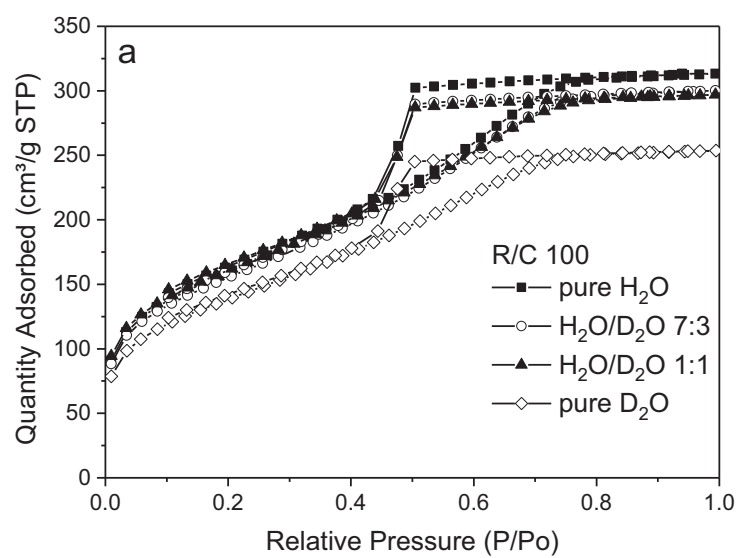

\section{Sample characterisation}

Nitrogen adsorption/desorption measurements were used to obtain textural properties for the RF gel samples prepared in this study. Nitrogen adsorption was performed at $-196^{\circ} \mathrm{C}$ using a Micromeritics ASAP 2420 surface area and porosity analyser. Before analysis, samples were outgassed under vacuum below $10 \mu \mathrm{m} \mathrm{Hg}$ at $50^{\circ} \mathrm{C}$ for $30 \mathrm{~min}$ and then at $110^{\circ} \mathrm{C}$ for $2 \mathrm{~h}$. Samples were characterised using a 40-point adsorption and 30-point desorption cycle for surface area $\left(\mathrm{m}^{2} / \mathrm{g}\right)$, using Brunaue-Emmett-Teller (BET) theory [26] and the Rouquerol correction for microporous samples [27]; total pore volume $\left(\mathrm{cm}^{3} / \mathrm{g}\right)$ was calculated from the equilibrium measurement of nitrogen adsorbed at $\sim 0.98$ bar (i.e., the saturation vaporous pressure of $\mathrm{N}_{2}$ at $77 \mathrm{~K}$ ), micropore volume $\left(\mathrm{cm}^{3} / \mathrm{g}\right)$ from the t-plot method [28] and average pore size $(\mathrm{nm})$ from the Barrett-Joyner-Halenda method [29].

\section{Results and discussion}

Nitrogen adsorption/desorption data presented in Figs. 2 and 3 show a difference between the textural properties of gels prepared with different ratios of $\mathrm{H}_{2} \mathrm{O}: \mathrm{D}_{2} \mathrm{O}$ in the reaction solution. The R/C 100 series exhibits a clear trend of decreasing accessible pore volume (Fig. 2a), determined from the highest point of the nitrogen adsorption isotherm, with increasing $\mathrm{D}_{2} \mathrm{O}$ concentration, while maintaining a similar pore size distribution (Fig. 2b). The isotherms obtained are classified as Type IV(a) [27] for all R/C 100 samples and the hysteresis loop (Type H2(a)) is indicative of a collection of narrow-necked pores [27]. Despite the invariance in pore diameter that is observed for the R/C 100 samples, the marked reduction in pore volume with increasing dilution by $\mathrm{D}_{2} \mathrm{O}$ is also evident in the pore size

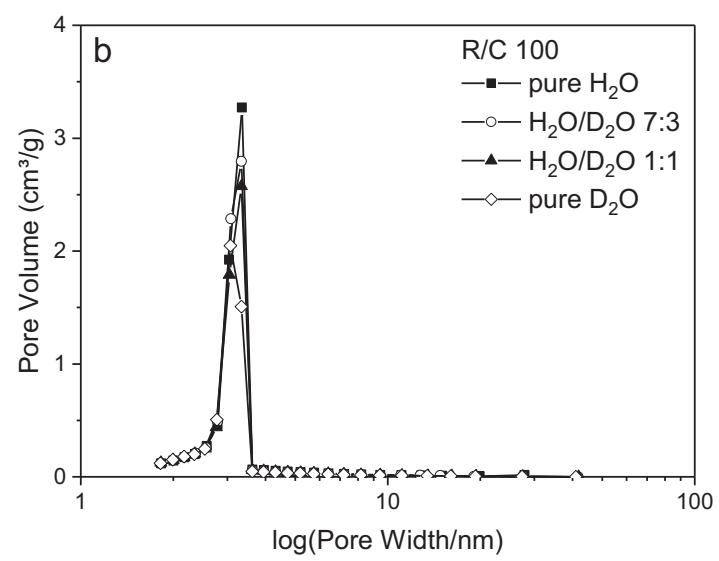

Fig. 2 a Nitrogen adsorption/desorption isotherms and $\mathbf{b}$ pore-size distributions gels prepared at R/C100 

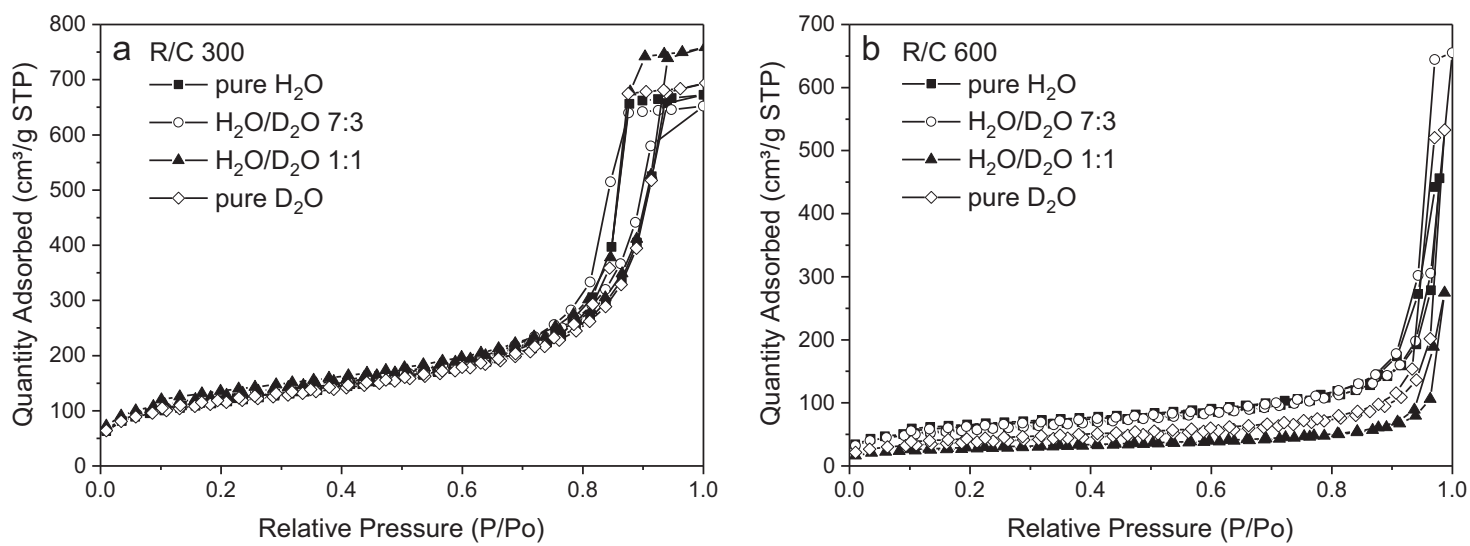

Fig. 3 Nitrogen adsorption/desorption isotherms for gels prepared at R/C ratios of a 300 and b 600

distribution series (Fig. 2b). By contrast, the samples with higher $\mathrm{R} / \mathrm{C}$ ratios do not seem to follow an evident trend. Again, there is obvious alteration of the magnitude of adsorption; however, for both R/C 300 and R/C 600, the absolute isotherm shape is unaltered by the presence of $\mathrm{D}_{2} \mathrm{O}$ (Fig. 3) and is also classified as Type IV(a) [27] in both cases. It is notable that the family of isotherms obtained for undeuterated RF gels are in agreement with those previously reported in the literature [2, 30]. Pore-size distributions are not shown for $\mathrm{R} / \mathrm{C}$ ratios 300 and 600 due to the lack of a distinct plateau at the higher pressures in the isotherm data. The points very close to partial pressure $P / P_{0}$ $=1$ are subject to variation, due to experimental errors at these conditions, including absolute temperature within the system and pressure differences; therefore, the estimated pore size distribution could be significantly affected and is not shown here. Correspondingly, we report the pore widths as the estimated average pore diameter. It is possible, however, to classify the hysteresis loops observed; in both cases these are Type H1 [27], which suggests a narrow range of pores, the limiting diameter of which may be an ink bottle type neck to the cavities, which is less pronounced for the higher $\mathrm{R} / \mathrm{C}$ ratio. This, in tandem with the results for R/C 100, suggests a move from well-defined narrow-necked pores to a network that has cavity filling issues, due to constrictions in the porous network.

Previous works have indicated the absorption of gases/ vapours into RF gel materials during adsorption measurements [31, 32], which is now believed to also extend to nitrogen adsorption at its condensation temperature. In addition, other authors have suggested that previous observations of microporous character in such gel materials indicate the occurrence of absorption in addition to adsorption in the system [33-35]; however, for most gaspolymer systems 'sorbed volumes are vanishingly small' and issues have been experienced previously for lowpressure experimental arrangements due to the 'low solubility of permanent gases in polymers', which includes nitrogen gas [31]. The RF gels studied here exhibit a high degree of crosslinking within their structures, which has been shown to reduce the degree of diffusion in polyethylene materials [36]; hence, similar behaviour would be expected here and compounds the expected low diffusivity for a polar organic material and a non-polar gas, such as nitrogen. The use of alternative techniques to estimate surface area have shown widely different correlations when compared with BET surface area [33, 35, 37, 38], suggesting that there are limitations in any selected technique, whereas other authors have also highlighted the potential of microporous materials including carbonaceous samples, to undergo deformation during the adsorption of probe gases including nitrogen [39]. It may therefore be argued that as the adsorption methods adopted here use a final pressure close to the saturated vapour pressure of nitrogen at $77 \mathrm{~K}$, all porous voids are filled within the process, and that the absorption character of the materials studied here can be quantified by the microporous character observed within the material. By assuming that this portion of the uptake is due to absorption, the remaining nitrogen uptake can be ascribed to adsorption only processes. Comparison of the data obtained on this basis also indicates that there is little difference observed for these materials.

In order to understand the differences exhibited by the gels prepared at different concentrations of $\mathrm{D}_{2} \mathrm{O}$, it is important to consider which factors are changing within the reaction system, i.e., the substitution of $\mathrm{H}_{2} \mathrm{O}$ by $\mathrm{D}_{2} \mathrm{O}$, and the potential influence that this may have on materials development. The impact of the introduction of $\mathrm{D}_{2} \mathrm{O}$ can be twofold within the reaction system; first, it can act as a solvent for the reaction matrix. An additional issue with this factor is that the condensation reaction between the hydroxymethyl derivatives, formed by reaction of resorcinol and formaldehyde, forms water as a byproduct, which, in turn, would dilute the $\mathrm{D}_{2} \mathrm{O}$ concentration as the reaction proceeds. 

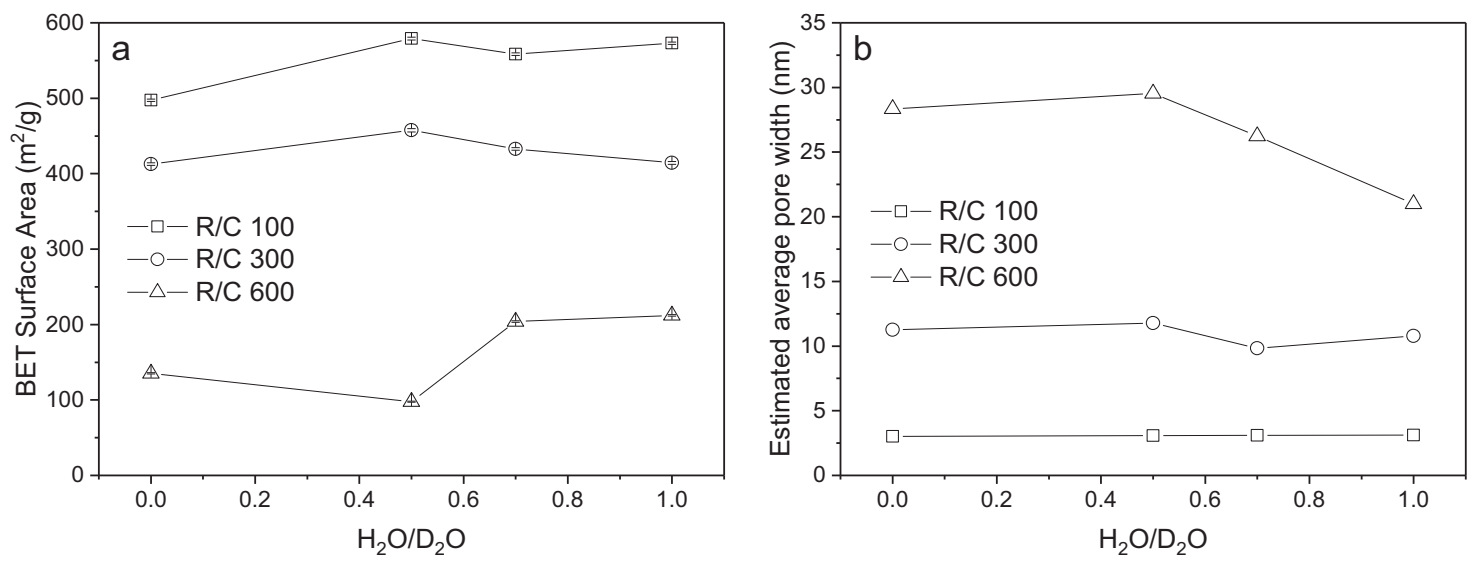

Fig. 4 a BET surface area and b estimated average pore width from Barrett-Joyner-Halenda method vs $\mathrm{H}_{2} \mathrm{O} / \mathrm{D}_{2} \mathrm{O}$ v/v ratio

Hence, the presence of $\mathrm{D}_{2} \mathrm{O}$ would have a more pronounced effect on the early stages of the synthesis, rather than the latter steps. The RF gels prepared with higher R/C ratios, especially R/C 600 , result in a very weak structure, which is more prone to shrinkage during the drying process. This can lead to higher variation of sample structure and character, and a reduction in the noticeable effect of $\mathrm{D}_{2} \mathrm{O}$ presence. The second impact of $\mathrm{D}_{2} \mathrm{O}$ is in its role in isotopic exchange. The -OH groups of methylene glycol (hydrated formaldehyde) and hydroxymethyl derivatives of resorcinol contain acidic hydrogen atoms that can be exchanged with deuterium atoms from $\mathrm{D}_{2} \mathrm{O}$. Using mass spectroscopy, Efimova et al. [40] have shown that majority of the hydrogen-deuterium $(\mathrm{H}-\mathrm{D})$ exchange for proteins takes place within a minute. The O-D bond is slightly shorter and is known to be stronger than the corresponding O-H bond [13], which would have an effect on the polycondensation reactions within the RF gel systems. A larger quantity of deuterium atoms exchanged into positions in the hydroxymethyl groups can therefore lead to a decrease in polycondensation reaction kinetics. At lower R/C ratios, the RF sample gels much faster than its higher R/C analogues [2]. This means that the $\mathrm{H}-\mathrm{D}$ exchange at the hydroxyl groups will have less time to occur at lower R/C ratios; thus, isotopic exchange will have a less pronounced effect on the final gel structure. In this work, the R/C 100 samples show a difference in magnitude of adsorption but no differences in isotherm type, hysteresis loop shape or average pore diameter; hence, it can be reasoned that the changes described above have little effect in terms of exchange, whereas the difference may be related to the role of $\mathrm{D}_{2} \mathrm{O}$ as a solvent. In the previous work of Gaca et al. [8], $\mathrm{R} / \mathrm{C}$ ratios even lower than 100 were used, which suggests there would be an even less pronounced effect with regards to $\mathrm{H}-\mathrm{D}$ exchange. They have also observed a relatively quick drop in reagent concentration [8], indicating that the initial speciation takes place early on and would not be significantly influenced by the presence of $\mathrm{D}_{2} \mathrm{O}$ in the system.
In accordance with the results discussed above, it can be seen (Fig. 4) that samples prepared with R/C 100 show little variation in both BET surface area and estimated average pore diameter with decreasing $\mathrm{D}_{2} \mathrm{O}$ content compared with higher $\mathrm{R} / \mathrm{C}$ ratios. There is marked variation for samples prepared using R/C 600 and it is likely to be that ratios above this value would result in greater variance in the resulting gels. It may also be the case that the large changes in character for the higher $\mathrm{R} / \mathrm{C}$ ratios, most heavily influenced by $\mathrm{D}_{2} \mathrm{O}$ concentration, exacerbate the differences observed in the final volume of nitrogen adsorbed as the materials become weak and prone to manufacturing effects; this could also explain the disparity noted in the estimated average pore diameter, which show a marked increase in variance as $\mathrm{R} / \mathrm{C}$ is increased. A summary of textural properties obtained from nitrogen adsorption is also presented in Table 1 and the whole suite of results suggest that the use of $\mathrm{D}_{2} \mathrm{O}$ within an RF gel matrix has a minor effect on textural characteristics at low concentration, especially when coupled with low $\mathrm{R} / \mathrm{C}$ ratio.

\section{Conclusions}

By studying the effect of a gradual replacement of $\mathrm{H}_{2} \mathrm{O}$ by $\mathrm{D}_{2} \mathrm{O}$ in the synthetic matrix of RF gel synthesis on final material textural characteristics, it has been shown that the presence of $\mathrm{D}_{2} \mathrm{O}$ has only a minor influence on the end gel structure obtained, which becomes less pronounced as R/C ratio decreases. This effect is most likely caused by the two concurrent roles that $\mathrm{D}_{2} \mathrm{O}$ has in the synthetic mixture. First, isotopic exchange will occur between hydrogen atoms of the hydroxyl groups present in the intermediate species and the deuterium atoms of $\mathrm{D}_{2} \mathrm{O}$; this interchange will alter the kinetics of the condensation stage of the reaction due to the difference in bond strength. Second, $\mathrm{D}_{2} \mathrm{O}$ will also act as a solvent, an effect that will be altered by dilution effects as 
Table 1 Textural properties of gels prepared with R/C ratios of 100 , 300 and 600 and different $\mathrm{H}_{2} \mathrm{O} / \mathrm{D}_{2} \mathrm{O}$ v/v ratios

\begin{tabular}{llllll}
\hline $\mathrm{R} / \mathrm{C}$ & $\begin{array}{l}\mathrm{H}_{2} \mathrm{O} / \\
\mathrm{D}_{2} \mathrm{O}\end{array}$ & $\begin{array}{l}\mathrm{BET} \\
\text { Surface } \\
\text { area }\left(\mathrm{m}^{2} /\right. \\
\mathrm{g})\end{array}$ & $\begin{array}{l}\text { Total pore } \\
\text { volume } \\
\left(\mathrm{cm}^{3} / \mathrm{g}\right)\end{array}$ & $\begin{array}{l}\text { Micropore } \\
\text { volume }\left(\mathrm{cm}^{3} /\right. \\
\mathrm{g})\end{array}$ & $\begin{array}{l}\text { Estimated } \\
\text { average pore } \\
\text { width }(\mathrm{nm})\end{array}$ \\
\hline 100 & $1: 0$ & $573(2)$ & 0.48 & $0.0494(4)$ & 3 \\
& $7: 3$ & $558(2)$ & 0.46 & $0.0477(5)$ & 3 \\
& $1: 1$ & $579(2)$ & 0.46 & $0.0613(6)$ & 3 \\
& $0: 1$ & $497(1)$ & 0.39 & $0.0425(5)$ & 3 \\
300 & $1: 0$ & $414(2)$ & 1.04 & $0.0480(5)$ & 11 \\
& $7: 3$ & $433(2)$ & 1.01 & $0.0495(4)$ & 10 \\
& $1: 1$ & $458(2)$ & 1.17 & $0.0646(5)$ & 12 \\
& $0: 1$ & $431(2)$ & 1.07 & $0.0517(3)$ & 11 \\
600 & $1: 0$ & $212(1)$ & 0.71 & $0.0352(2)$ & 21 \\
& $7: 3$ & $204(1)$ & 1.01 & $0.0300(3)$ & 26 \\
& $1: 1$ & $98(1)$ & 0.42 & $0.0179(2)$ & 30 \\
& $0: 1$ & $135(1)$ & 0.82 & $0.0200(2)$ & 28 \\
\hline
\end{tabular}

$\mathrm{H}_{2} \mathrm{O}$ is generated by condensation reactions, nevertheless changing the environment in which the formation and growth of gel clusters takes place. Higher R/C ratio systems will be more affected by isotopic substitution due to a combination of long gelation times and the weaker structures generally formed as catalyst quantity is decreased. By contrast, low R/C systems would be less influenced by the inclusion of $\mathrm{D}_{2} \mathrm{O}$ into the synthetic matrix, retaining most of the core characteristics irrespective of additive concentration, as shown above. Herein, we have shown that the use of $\mathrm{D}_{2} \mathrm{O}$ in NMR studies of RF gels is viable, with only a minor impact on final gel textural character, and is particularly suitable at the concentrations and lower $\mathrm{R} / \mathrm{C}$ ratios used in previous studies.

\section{Compliance with ethical standards}

Conflict of interest The authors declare that they have no conflict of interest.

Open Access This article is distributed under the terms of the Creative Commons Attribution 4.0 International License (http://crea tivecommons.org/licenses/by/4.0/), which permits unrestricted use, distribution, and reproduction in any medium, provided you give appropriate credit to the original author(s) and the source, provide a link to the Creative Commons license, and indicate if changes were made.

\section{References}

1. Pekala RW (1989) Organic aerogels from the polycondensation of resorcinol with formaldehyde. J Mater Sci 24(9):3221-3227

2. Taylor SJ, Haw MD, Sefcik J, Fletcher AJ (2014) Gelation mechanism of resorcinol-formaldehyde gels investigated by dynamic light scattering. Langmuir 30(34):10231-10240
3. Gaca KZ, Sefcik J (2013) Mechanism and kinetics of nanostructure evolution during early stages of resorcinol-formaldehyde polymerisation. J Colloid Interf Sci 406:51-59

4. Al-Muhtaseb SA, Ritter JA (2003) Preparation and properties of resorcinol-formaldehyde organic and carbon gels. Adv Mater 15 (2): 101

5. Morales-Torres S, Maldonado-Hódar FJ, Pérez-Cadenas AF, Carrasco-Marín F (2010) Textural and mechanical characteristics of carbon aerogels synthesized by polymerization of resorcinol and formaldehyde using alkali carbonates as basification agents. Phys Chem Chem Phys 12(35):10365-10372

6. Taylor SJ, Haw MD, Sefcik J, Fletcher AJ (2015) Effects of secondary metal carbonate addition on the porous character of resorcinol-formaldehyde xerogels. Langmuir 31 (50):13571-13580

7. Gaca KZ, Parkinson JA, Lue L, Sefcik J (2014) Equilibrium speciation in moderately concentrated formaldehyde-methanol water solutions investigated using C-13 and $\mathrm{H}-1$ nuclear magnetic resonance spectroscopy. Ind Eng Chem Res 53(22):9262-9271. https://doi.org/10.1021/ie403252x

8. Gaca KZ, Parkinson JA, Sefcik J (2017) Kinetics of early stages of resorcinol-formaldehyde polymerization investigated by solution-phase nuclear magnetic resonance spectroscopy. Polymer 110:62-73

9. Werstler DD (1986) Quantitative C-13 NMR characterization of aqueous formaldehyde resins .2. Resorcinol-formaldehyde resins. Polymer 27(5):757-764

10. Christiansen AW (2000) Resorcinol-formaldehyde reactions in dilute solution observed by carbon-13 NMR spectroscopy. J Appl Polym Sci 75(14):1760-1768

11. Lewicki JP, Fox CA, Worsley MA (2015) On the synthesis and structure of resorcinol-formaldehyde polymeric networks - precursors to 3D-carbon macroassemblies. Polymer 69:45-51

12. Rivlin M, Eliav U, Navon G (2015) NMR studies of the equilibria and reaction rates in aqueous solutions of formaldehyde. J Phys Chem B 119(12):4479-4487

13. Nemethy G, Scheraga HA (1964) Structure of water and hydrophobic bonding in proteins. IV. The thermodynamic properties of liquid deuterium oxide. J Chem Phys 41(3):680-689

14. Franks F (1972) Water: A Comprehensive Treatise, vol. 1. Plenum Press, New York and London, (1972)

15. Shirota H, Pal H, Tominaga K, Yoshihara K (1996) Deuterium isotope effect on the solvation dynamics of methanol: $\mathrm{CH}_{3} \mathrm{OH}$, $\mathrm{CH}_{3} \mathrm{OD}, \mathrm{CD}_{3} \mathrm{OH}$, and $\mathrm{CD}_{3} \mathrm{OD}$. J Phys Chem 100 (35):14575-14577

16. Mills R, Harris K (1976) The effect of isotopic substitution on diffusion in liquids. Chem Soc Rev 5:215-231

17. Forsythe KM, Makri N (1998) Path integral study of hydrogen and deuterium diffusion in crystalline silicon. J Chem Phys 108 (16):6819-6828

18. Szabo Z, Grenthe I (1998) Mechanisms of ligand substitution reactions in ternary dioxouranium (VI) complexes. Inorg Chem 37 (24):6214-6221

19. Stutz J, Ezell M, Finlayson-Pitts B (1997) Inverse kinetic isotope effect in the reaction of atomic chlorine with $\mathrm{C}_{2} \mathrm{H}_{4}$ and $\mathrm{C}_{2} \mathrm{D}_{4}$. $\mathrm{J}$ Phys Chem A 101(49):9187-9190

20. Pyun S-I, Lim C, Kim K-B (1994) An investigation of the electrochemical kinetics of deuterium insertion into a Pd membrane electrode in $0.1 \mathrm{M} \mathrm{LiOD}$ solution by the ac impedance technique. J Alloy Compd 203:149-156

21. Fletcher AJ, Thomas KM (2007) Kinetic isotope quantum effects in the adsorption of $\mathrm{H}_{2} \mathrm{O}$ and $\mathrm{D}_{2} \mathrm{O}$ on porous carbons. J Phys Chem C 111(5):2107-2115

22. Efimova Y, Haemers S, Wierczinski B, Norde W, Van Well A (2007) Stability of globular proteins in $\mathrm{H}_{2} \mathrm{O}$ and $\mathrm{D}_{2} \mathrm{O}$. Biopolymers 85(3):264-273 
23. Dougan L, Koti ASR, Genchev G, Lu H, Fernandez JM (2008) A single-molecule perspective on the role of solvent hydrogen bonds in protein folding and chemical reactions. ChemPhysChem 9 (18):2836-2847

24. Huang J, Sung J, Wu X-L (1989) The effect of H2O and D2O on a water-in-oil microemulsion. J Colloid Interf Sci 132(1):34-42

25. GrenierLoustalot MF, Larroque S, Grande D, Grenier P, Bedel D (1996) Phenolic resins .2. Influence of catalyst type on reaction mechanisms and kinetics. Polymer 37(8):1363-1369

26. Brunauer S, Emmett PH, Teller E (1938) Adsorption of gases in multimolecular layers. J Am Chem Soc 60:309-319

27. Thommes M, Kaneko K, Neimark AV, Olivier JP, RodriguezReinoso F, Rouquerol J, Sing KSW (2015) Physisorption of gases, with special reference to the evaluation of surface area and pore size distribution (IUPAC Technical Report). Pure Appl Chem 87 (9-10):1051-1069

28. Lowell S, Shields JE, Thomas MA, Thommes M (2004) Micropore Analysis. In: Characterization of Porous Solids and Powders: Surface Area, Pore Size and Density. The Netherlands, Springer, pp 129-156

29. Barrett EP, Joyner LG, Halenda PP (1951) The determination of pore volume and area distributions in porous substances. I. Computations from nitrogen isotherms. J Am Chem Soc 73 (1):373-380. https://doi.org/10.1021/ja01145a126

30. Mirzaeian M, Hall PJ (2009) The control of porosity at nano scale in resorcinol formaldehyde carbon aerogels. J Mater Sci 44 (10):2705-2713

31. Vieth WR (1991) Diffusion in and through Polymers: Principles and Applications. Hanser, Munich, Vienna, New York, Barcelona
32. Strobl G (2007) The semicrystalline state. The Physics of Polymers: Concepts for Understanding Their Structures and Behavior. Berlin, Springer, pp 165-222

33. Berthon S, Barbieri O, Ehrburger-Dolle F, Geissler E, Achard P, Bley F, Hecht A-M, Livet F, Pajonk GM, Pinto N (2001) DLS and SAXS investigations of organic gels and aerogels. J Non-Cryst Solids 285(1):154-161

34. Saliger R, Bock V, Petricevic R, Tillotson T, Geis S, Fricke J (1997) Carbon aerogels from dilute catalysis of resorcinol with formaldehyde. J Non-Cryst Solids 221(2):144-150

35. Czakkel O, Marthi K, Geissler E, László K (2005) Influence of drying on the morphology of resorcinol-formaldehyde-based carbon gels. Microporous Mesoporous Mater 86(1):124-133

36. Michaels AS, Bixler HJ (1961) Solubility of gases in polyethylene. J Polym Sci Part A Polym Chem 50(154):393-412

37. Schaefer DW, Pekala R, Beaucage G (1995) Origin of porosity in resorcinol-formaldehyde aerogels. J Non-Cryst Solids 186:159-167

38. Brandt R, Fricke J (2004) Acetic-acid-catalyzed and subcritically dried carbon aerogels with a nanometer-sized structure and a wide density range. J Non-Cryst Solids 350:131-135

39. Balzer C, Braxmeier S, Neimark AV, Reichenauer G (2015) Deformation of microporous carbon during adsorption of nitrogen, argon, carbon dioxide, and water studied by in situ dilatometry. Langmuir 31(45):12512-12519

40. Efimova Y, van Well A, Hanefeld U, Wierczinski B, Bouwman W (2005) On the scattering length density of proteins in $\mathrm{H}_{2} \mathrm{O} / \mathrm{D}_{2} \mathrm{O}$ : Determination of $\mathrm{H}-\mathrm{D}$ exchange using $\mathrm{ES}^{+} \mathrm{I}-\mathrm{MS}$. J Radioanal Nucl Chem 264(2):271-275 